\title{
A IMPORTÂNCIA DO DESENVOLVIMENTO PSICOMOTOR NA EDUCAÇÃO INFANTIL
}

\author{
Kellynay Lima Souza ${ }^{1}$
}

Luana Reverti de Araújo Silva²

\begin{abstract}
RESUMO
O presente estudo objetivou conhecer a importância do desenvolvimento da psicomotricidade na Educação Infantil. Sabe-se que a psicomotricidade está presente em todas as atividades que desenvolvem a motricidade das crianças, contribuindo para o conhecimento e o domínio de seu próprio corpo, o que a torna indispensável para o desenvolvimento global e a base fundamental para 0 processo de aprendizagem dos indivíduos. Este estudo bibliográfico se fundamenta, em autores que preconizam a Educação psicomotora como sendo a base para a Educação Infantil, com destaque em Le Boulch (1986; 1987; 2001). Buscamos também a fundamentação em Silva (2011), Wallon (1963;1981), Souza (2012), nos conceitos do Ministério da educação (1998), dentre outros autores que definem a psicomotricidade e enfatizam sua importância no desenvolvimento Infantil. Observamos nesse estudo, que a estimulação psicomotora correta contribui para uma aprendizagem completa e significativa e é de extrema importância na Educação Infantil, pois desempenha um papel fundamental para as aprendizagens.
\end{abstract}

Palavras-chave: Psicomotricidade; Educação Infantil; Motricidade.

1 Mestranda em Educação pela Faculdade interamericana de Ciencias Sociales. Asunción-PY. Contatos: E-mail - kellynay@bol.com.br (77) 991099551

2 Mestranda em Educação pela Faculdade interamericana de Ciencias Sociales. Asunción-PY. Contatos: E-mail - revertiluana4@gmail.com (77) 991318876 


\section{INTRODUÇÃO}

A psicomotricidade está presente em todas as atividades que desenvolvem a motricidade das crianças, contribuindo para o conhecimento e o domínio de seu próprio corpo. Ela constitui-se como um fator indispensável ao desenvolvimento global e uniforme ainda na infância, sendo a base fundamental para o processo de aprendizagem dos indivíduos.

Gallahue (2003) defende que uma criança que conhece as suas habilidades e o seu corpo, e como ele se move no espaço, desenvolve estruturas de cognição que podem facilitar as suas atividades de caráter cognitivo.

Nesse sentido, a Educação Infantil tem papel fundamental no desenvolvimento do sistema psicomotor da criança, uma vez que é nas séries iniciais que se busca experiências em seu próprio corpo, formando conceitos e organizando o esquema corporal.

A abordagem da psicomotricidade permitirá a compreensão da forma como a criança toma consciência do seu corpo e das possibilidades de se expressar por meio dele, localizando-se no tempo e no espaço.

De acordo com Le Boulch (1986), a educação psicomotora condiciona todos os aprendizados pré-escolares, levando a criança a tomar consciência do seu corpo no espaço e no tempo, adquirindo habilidades de coordenar seus gestos e movimentos. Além disso, previne dificuldades que possam surgir durante o processo de ensino-aprendizagem.

A Educação Infantil é muito importante para o desenvolvimento global da criança. Nela, os aspectos que envolvem a psicomotricidade favorecem 0 processo ensino-aprendizagem já que compreendem a educação como algo mais amplo do que a simples transmissão de conhecimentos.

Assim, surgiu a necessidade de saber qual a importância do desenvolvimento da psicomotricidade na Educação Infantil?

Diante desse contexto essa pesquisa nasce com o objetivo de mostrar a importância da psicomotricidade na Educação Infantil, e o quanto um bom desenvolvimento psicomotor é importante para a criança, pois através dessas 
atividades, lúdicas ou não, a crianças estabelecem relações com os outros, consigo mesma e com o mundo.

Essa pesquisa caracteriza-se por um estudo bibliográfico, que utiliza-se de vários autores que discute o tema abordado.

\section{A PSICOMOTRICIDADE E SUA DEFINIÇÃO}

Várias são as definições para a Psicomotricidade. Cada autor coloca 0 seu olhar ao defini-la. A Sociedade Brasileira de Psicomotricidade (2003) diz que Psicomotricidade, é um termo empregado para uma concepção de movimento organizado e integrado em função das experiências vividas pelo sujeito, cuja ação é resultante de sua individualidade, sua linguagem e sua socialização.

Para Lapierre e Le Boulch, apud Oliveira (2001), a educação psicomotora deve ser uma formação de base indispensável a toda criança. Fonseca (2004) completa dizendo que a psicomotricidade, na contemporaneidade, constitui uma abordagem multidisciplinar do corpo e da motricidade humana. Seu objeto é o sujeito humano total e suas relações com o corpo; sejam elas integradoras, emocionais, simbólicas ou cognitivas. Nesse contexto, a psicomotricidade assume uma dimensão educacional preventiva.

Assim,

A prática psicomotora é dirigida à criança porque nela se encontra a plenitude da expressividade motora, nela ocorre a união entre estrutura motora, afetiva e as possibilidades cognitivas. Isso significa que a criança, através da ação (sensório-motora) (...) explora o mundo do espaço, dos objetos e das pessoas (SÁNCHES, 2003, p. 73).

Dessa forma, a relação entre a psicomotricidade e a Educação Infantil é considerada expressivamente essencial para a criança sob a perspectiva sensório-motora.

O educador deve considerar a expressividade como forma de desenvolver integralmente a criança. Ela apreende o conhecimento e se expressa de forma única, externalizando o seu pensamento e construindo uma identidade frente ao mundo em que vive. Ou seja, 
o movimento para a criança pequena significa muito mais do que mexer partes do corpo ou deslocar-se no espaço. A criança se expressa e se comunica por meio dos gestos e das mímicas faciais e interage utilizando fortemente o apoio do corpo. A dimensão corporal integra-se ao conjunto da atividade da criança. $\mathrm{O}$ ato motor faz-se presente em suas funções expressiva, instrumental ou de sustentação às posturas e aos gestos (BRASIL,1998, p.18).

Nesse sentido, a Educação psicomotora acompanha a criança em todo o seu percurso maturativo; que vai desde o desenvolvimento de sua expressividade motora até a sua capacidade de pensar vários aspectos de uma situação simultaneamente. Assim, a educação psicomotora deve ser considerada como uma educação de base para a educação infantil, desde a préescola até as séries iniciais (LE BOULCH, 1986).

Além de direcionar o processo de alfabetização, leva a criança a tomar consciência de seu corpo, da lateralidade, a se situar no espaço, a dominar seu tempo, a adquirir habitualmente a coordenação de seus gestos e movimentos, ou seja, a dominar seus movimentos psicomotores.

Nesse contexto, a psicomotricidade não é apenas uma prática preventiva, mas, sobretudo, educativa, que contribui para a aquisição da autonomia, facilitando assim o processo de aprendizagem.

A psicomotricidade constitui-se então como um suporte para as aprendizagens cognitivas, em que o movimento serve como recurso pedagógico, auxiliando e facilitando o sucesso da criança nos mais diversos campos do conhecimento.

É na Educação Infantil que a psicomotricidade tem sua importância aumentada. Aqui, deve-se enfatizar a atividade motora global, uma vez que o movimento é de fundamental importância para desenvolver ou fazer surgir as inúmeras habilidades motoras da criança. Nessa fase, há um rápido aperfeiçoamento e entendimento dos movimentos adquiridos.

(...) o movimento é a única expressão e o primeiro instrumento do psiquismo. O movimento (ação), pensamento e linguagem são unidades inseparáveis. O movimento é o pensamento em ato, e o pensamento é o movimento em ato (WALLON, 1979, p.33). 
Faz-se necessário, então, que o professor da Educação Infantil possua um conhecimento satisfatório sobre o desenvolvimento psicomotor das crianças, uma vez que a psicomotricidade se apresenta como um meio a ser utilizado por ele. Assim, sentir-se-á preparado mediante as possíveis dificuldades que surgirem ao longo do processo de ensino aprendizagem.

Observa-se, dessa maneira, um novo caminho, uma nova perspectiva quando se trata do desenvolvimento global da criança, que faz surgir a necessidade nas escolas de um modo geral e, principalmente, nas de Educação Infantil de um trabalho com qualidade na área motora, para que a criança vivencie todas as etapas de seu desenvolvimento.

A Psicomotricidade, segundo Oliveira (2007), é um caminho. É o desejo de fazer, de querer fazer e de poder fazer. Nesse sentido, o homem não é exclusivamente um ser motor ou somente um ser psíquico. $O$ homem é psicomotor. É a articulação do ter, do ser, do querer, do poder ser e fazer.

A Educação Infantil tem a função de fornecer às crianças os principais requisitos básicos para a sua aprendizagem e desenvolvimento, uma vez que a aprendizagem da criança está diretamente ligada ao desenvolvimento psicomotor, e este é um importante fator para unir a psicomotricidade com a educação.

Assim, a psicomotricidade na Educação Infantil abre espaço para que as crianças possam desenvolver habilidades motoras que as levem a aprender, a conhecer seu próprio corpo e a se movimentar expressivamente, bem como desenvolver habilidades motoras finas.

De certa maneira, ao apropriar-se do seu saber corporal, deve-se também incluir as dimensões do movimento que indiquem estados afetivos até representações de movimentos mais elaborados de sentidos e ideias, oferecendo um caminho para trocar afetividades que facilitem a comunicação e a expressão. 


\section{A PSICOMOTRICIDADE}

A história da psicomotricidade nasce com a história do corpo. O termo apareceu no discurso médico em princípios do século XX, com trabalhos de Dupré (COSTE, 1992), na França, por volta de 1920, significando um entrelaçamento entre o movimento e o pensamento. Assim, ela passou a ser a ciência da educação que educa o movimento ao mesmo tempo em que põem em jogo as funções da inteligência.

A Psicomotricidade existe nos menores gestos e em todas as atividades que desenvolvem a motricidade da criança, visando o conhecimento e o domínio do seu próprio corpo. Por isso, dizemos que é um fator essencial e indispensável ao desenvolvimento global e uniforme da criança.

As crianças da atualidade não são as mesmas de antigamente, pois vivemos em um momento de profundas e rápidas transformações, principalmente quando falamos da aquisição de conhecimento. Assim, as crianças precisam ser entendidas em sua totalidade e como ser indissociável de sua cultura, ação, movimento, cognição e espiritualidade.

Hoje, o mundo está crescendo muito rápido e as exigências sociais com o ser humano estão muito grandes. A sociedade quer pessoas críticas, atuantes, que saibam se expressar, posicionando-se e comunicando-se com clareza. Com isso, vemos a grande necessidade do desenvolvimento motor no processo ensino-aprendizagem para que o ser humano possa enfrentar as situações do dia a dia com maior capacidade e desenvoltura.

Segundo Piaget (1996), as atividades sensório-motoras são de suma importância para o desenvolvimento da inteligência. Assim, a partir da Educação Infantil, deve ser dada ênfase à atividade motora global, uma vez que o movimento é fundamental para desenvolver ou fazer surgir inúmeras habilidades motoras e é nesse momento que há um rápido aperfeiçoamento dos movimentos adquiridos, favorecendo a combinação entre eles e uma melhor qualidade.

Visando à formação integral e não fragmentada da criança, acreditamos que uma das ferramentas que contribuirá para isso é a Psicomotricidade. Essa ciência, de fato, traz grandes contribuições se aplicada com objetivo e 
direcionamento. Desse modo, a educação Psicomotora deveria fazer parte de todo o currículo da Educação Infantil.

O registro e um olhar bem atentos são formas de avaliação concreta na observação desse desenvolvimento. Cada criança é única e traz dentro de si uma história que passa pela experiência corporal (LE BOLCHE, 1982).

Assim, a escola deve proporcionar às crianças um trabalho psicomotor orientado, que contemple a formação de base indispensável em seu desenvolvimento motor, afetivo e psicológico, dando oportunidade para que, por meio de jogos e de atividades lúdicas, eles se conscientizem sobre o seu próprio corpo.

Conforme Le Boulch (1992), a Psicomotricidade se dá por meio de ações educativas de movimentos espontâneos e atitudes corporais da criança, proporcionando-lhe uma imagem de corpo que contribua para a formação de sua personalidade. É, portanto, uma prática pedagógica que visa contribuir para o desenvolvimento integral da criança no processo de ensino-aprendizagem, favorecendo os aspectos físicos, mentais, afetivo-emocionais e socioculturais, buscando estar sempre condizente com a realidade dos educandos.

Acrescenta ainda que

\begin{abstract}
A educação psicomotora deve ser enfatizada e iniciada na escola primária. Ela condiciona todos os aprendizados pré-escolares e escolares; leva a criança a tomar consciência de seu corpo, da lateralidade, a situar-se no espaço, a dominar o tempo, a adquirir habilmente a coordenação de seus gestos e movimentos, ao mesmo tempo em que desenvolve a inteligência. Deve ser praticada desde a mais tenra idade, conduzida com perseverança, permite prevenir inadaptações, difíceis de corrigir quando já estruturadas. (LE BOULCH, 1984, p. 24).
\end{abstract}

Na Educação infantil, é imprescindível que os profissionais analisem sua prática, pois não basta ter apenas conhecimento, é preciso mediar o processo de ensino-aprendizagem para que seja rico de significado e pleno no uso da Educação Psicomotora.

Dessa forma, o trabalho na Educação infantil deve favorecer o desenvolvimento da criança e a aquisição de conhecimentos, proporcionando 
um lugar de brincar e de aprender, uma vez que é brincando que a criança aprende.

Segundo Neto (2001), o brincar, por meio de movimentos, permite à criança um conjunto de relações (sujeito, as coisas, o espaço) necessárias ao seu desenvolvimento motor, aprendendo a perceber e a interagir o vívido, o operatório e o mental.

A riqueza de informações é processada de forma contínua e em plasticidade, permitindo mais tarde uma cultura motora fundamental à tarefas mais precisas e que solicitem maior exigência das diversas estruturas ou componentes da motricidade. Assim, as brincadeiras fazem parte do patrimônio lúdico-cultural, traduzindo valores, costumes e formas de pensamento e ensinamentos que proporocionam às crianças uma cultura motora fundamental ao seu desenvolvimento e a sua aprendizagem.

A educação eficiente deve proporcionar às crianças momentos com essas atividades, de forma orientada, e uma prática voltada para o desenvolvimento da autonomia, para que estas crianças possam usufruí-la nas diversas fases de sua vida, de maneira a atender às suas necessidades intrínsecas.

Desse modo, a psicomotricidade é indispensável ao processo educativo, pois tem o intuito de ampliar nos alunos um desenvolvimento psicomotor satisfatório e, ao mesmo tempo, contribuir para uma evolução psicossocial e para o sucesso escolar.

\subsection{Elementos básicos da psicomotricidade}

A psicomotricidade é concebida, hoje, como a integração superior da motricidade, relação inteligível entre a criança e o meio, instrumento por meio do qual a consciência se forma e materializa-se. A função motora, o desenvolvimento intelectual e o desenvolvimento afetivo na criança estão totalmente relacionados. A psicomotricidade quer, justamente, destacar a relação existente entre a motricidade, a mente e a afetividade e facilitar a apreensão global da criança. 
Segundo Francisco Rosa Neto (2002), os elementos básicos da motricidade são: a motricidade fina, a motricidade global, o equilíbrio, o esquema corporal, a organização espacial, a organização temporal e a lateralidade.

a) A motricidade fina diz respeito à habilidade manual e à destreza manual e constitui um aspecto particular da coordenação global; ou seja, é a capacidade para executar movimentos finos com controle e destreza (por exemplo, usar uma tesoura ou um lápis). Brandão (apud OLIVEIRA, 2007, p. 42) analisa a mão como um dos instrumentos mais úteis para a descoberta do mundo, afirmando que ela é um instrumento de ação à serviço da inteligência.

b) A motricidade global é definida como atividades de grandes grupos musculares e dependem principalmente do equilíbrio postural, pois diz respeito à capacidade de execução de diferentes movimentos em diversos segmentos corpóreos ao mesmo tempo. Ou seja, a criança consegue ter uma maior consciência de seu corpo, adquire a dissociação de movimentos, possibilitando a realização de muitas práticas ao mesmo tempo. Podemos citar alguns exemplos de atividades que requerem uma boa coordenação motora global: engatinhar, pular, andar, correr, saltar, rolar, escalar etc.

c) O equilíbrio é uma das etapas mais importantes do desenvolvimento corporal, pois é ele que permite que a criança fique de pé, caminhe, corra ou faça qualquer outra atividade, tornando-se assim um dos sentidos essenciais ao dia a dia do indivíduo. Ou seja, é a capacidade de manter-se sobre uma base reduzida de sustentação do corpo, utilizando uma combinação adequada de ações musculares, parado ou em movimento.

O equilíbrio poderá ser de duas maneiras: estático (movimentos realizados sem movimentação das pernas; como ficar na ponta dos pés) ou dinâmico (feito em movimentação das pernas; como em uma corrida). Para ambos, é necessário um bom desenvolvimento infantil para que não haja impacto na fase adulta.

A ação com equilíbrio estático exige uma série de atividades internas (respiração, fixar um ponto etc.) para que seja possível realizá-lo. Por essa característica, o equilíbrio estático é mais difícil que o dinâmico, ao contrário do 
que muitos pensam. Em movimento, o corpo tende a se equilibrar de maneira mais natural do que ao estar parado.

d) O esquema corporal é compreendido como a relação consciente do corpo como meio de comunicação consigo mesmo e com o meio. O esquema corporal é um elemento básico indispensável para a formação da personalidade da criança. "É a representação relativamente global, científica e diferenciada que a criança tem de seu próprio corpo" (WALLON, 1981. p. 9). O esquema corporal engloba então o tônus muscular e a imagem corporal.

Para Wallon (1963), a função tônica depende constantemente das influências superiores e pode ser modificada pelo psíquico. O tono muscular é o suporte de sustentação para as emoções e, por meio da atividade tônica, a criança estabelece uma relação com o mundo exterior.

O estado tônico é um modo de relação. É uma tensão ligeira e permanente do músculo esquelético no seu estado de repouso, estando presente em todas as funções motrizes do organismo, tais como equilíbrio, coordenação e movimento. Portanto, tônus e psiquismo estão relacionados e representam dois aspectos de uma mesma função em uma relação pessoal, familiar e social.

Para Vayer (1979), a imagem corporal é o resultado complexo de toda a atividade cinética, a síntese de todas as mensagens, de todos os estímulos e de todas as ações que permitam à criança se diferenciar do mundo exterior e de fazer do "eu" o sujeito de sua própria existência. No esquema corporal, a criança entende a relação do seu corpo com o meio em que vive.

Assim, o esquema corporal resulta das experiências que possuímos provenientes do corpo e das sensações que experimentamos. É o resultado de uma construção mental que a criança realiza gradualmente de acordo com a maneira como usa o seu corpo. Com isso, podemos dizer que, por meio do esquema corporal, a criança se situa e se afirma, percebendo os seres e as coisas que a cercam, relacionando-se com o espaço em que vive.

O esquema corporal não é, portanto, um conceito aprendido, que se possa ensinar, não dependendo de treinamento. Ele se organiza pela experimentação e experiências do corpo da criança. É uma constante construção mental, de 
acordo com o uso que faz de seu corpo. Segundo Oliveira (1997), é um resumo e uma síntese de sua experiência corporal.

Ou seja,

É um elemento básico indispensável para a formação da personalidade da criança. É a representação relativamente global, científica e diferenciada que a criança tem de seu próprio corpo. (WALLON, 1974. p.9)

O próprio processo de maturação que ocorre no decorrer da infância, no dia a dia, em suas experiências vividas, está condicionado ao correto desenvolvimento do esquema corporal.

Desde os primeiros movimentos com que se relaciona com o mundo exterior, como a boca e com os objetos que experimenta o contato com tecidos, os primeiros passos e as primeiras quedas, tudo está em constante progresso, em constante modificação, para uma autoafirmação pelo conhecimento.

Segundo Le Boulch (1981. p. 74), o esquema corporal é dividido em etapas:

- A primeira etapa ou corpo vivido (até 3 anos de idade), corresponde à fase de inteligência sensório-motora de Piaget. Nessa fase, a criança não consegue se distinguir do meio ambiente, isto é, para ela, o meio ambiente faz parte dela mesma. À medida que cresce e com o maior amadurecimento de seu sistema nervoso, ela vai ampliando suas vivências e passa, gradualmente, a se diferenciar do meio ambiente e a perceber sua individualidade.

Oliveira (1997) considera essa etapa dominada pela experiência vivida pela criança, pela exploração do meio, por sua necessidade de investigação.

- A Segunda etapa, corpo percebido ou Descoberto (3 a 7 anos), compreende a organização do esquema corporal devido a uma maior maturação da "função de interiorização", que é definida como a possibilidade de deslocar sua atenção do meio ambiente para seu próprio corpo a fim de levar à tomada de consciência.

Essa interiorização permite a passagem do ajustamento espontâneo a um ajustamento controlado. Aqui, a criança passa a ter um maior domínio do corpo 
e, com isso, passa a aperfeiçoar e refinar seus movimentos, adquirindo maior coordenação dentro de um espaço e tempo determinado. Descobre sua dominância e, com ela, seu eixo corporal. O corpo passa a ser um ponto de referência para se situar e situar os objetos em seu espaço e tempo.

Nesse momento, assimila conceitos como embaixo, acima, direita, esquerda e adquire também noções temporais como a duração dos intervalos de tempo e de ordem e sucessão. Ao fim dessa fase, a criança pode ser considerada como pré-operatória, porque está submetida à percepção num espaço, em parte representado, mas ainda centralizado sobre o próprio corpo.

- A terceira etapa ou etapa do Corpo representado (7 a 12 anos) é a que compreende a estruturação do esquema corporal, pois já apresenta a noção do todo e das partes de seu corpo, conhece as posições e consegue movimentarse adequadamente no meio ambiente com um maior controle e domínio corporal.

A criança só dispõe de uma imagem mental do corpo em movimento a partir de 10/12 anos, significando que atingiu uma representação mental de uma sucessão motora, com a introdução do fator temporal. Sua imagem de corpo passa a ser antecipatória e não mais somente reprodutora, revelando um verdadeiro trabalho mental devido à evolução das funções cognitivas, correspondentes ao estágio preconizado por Piaget de operações concretas. É a fase da representação mental da imagem do corpo, que revela um trabalho mental em decorrência da evolução cognitiva.

e) A organização espacial pode ser definida como a capacidade que o indivíduo tem de situar-se e orientar-se em relação aos objetos, às pessoas e ao seu próprio corpo em um determinado espaço. Desse modo,

envolve a percepção do "eu" em relação aos objetos e o meio ambiente. É saber localizar o que está à direita ou à esquerda; à frente ou atrás; acima ou abaixo de si, ou ainda, um objeto em relação a outro. É ter noção do longe, perto, alto, baixo, longo, curto". (ASSUNÇÃO; COELHO,1997, p.91-96)

Essa percepção, para ser bem-sucedida, depende de uma boa maturidade psiconeurológica e cognitiva. Quando não estimulada, pode levar a uma dificuldade em encaixes, em montagens, em orientações dentro de um 
determinado espaço (como esbarrar-se com frequência, não ocupar a folha de um papel de forma harmoniosa, dificuldade em organizar seu traçado dentro de um limite), montar contas matemáticas, não seguir orientações como direita e esquerda e também orientar-se em um mapa geográfico.

\begin{abstract}
Adquirimos pouco a pouco a atitude de avaliar nossa relação com o espaço que nos rodeia e de ter em consideração as modificações dessa relação no curso dos deslocamentos que condicionam nossa orientação espacial. A percepção que temos do espaço que nos rodeia e das relações entre elementos que o compõem evolui e modifica-se com a idade e com a experiência. Essas relações chegam a ser, progressivamente, objetivas e independentes (ROSA NETO, 2002, p. 21).
\end{abstract}

f) A organização temporal é definida por Almeida (2008) como a capacidade que temos de distinguir a ordem e a duração dos acontecimentos como horas, dias, semanas, meses, anos e a memória de sucessão dos acontecimentos.

O transcorrer do tempo é definido pelos mais variados órgãos sensoriais dos corpos. Essa definição é estruturada em especial pela memória, a partir da qual se percebe a velocidade constante do tempo (o futuro, o passado e 0 presente). Isso implica dizer que a motricidade humana e suas relações com 0 corpo, com o espaço e com o tempo têm que estar estritamente ligadas. O corpo se coordena, movimenta-se sem interrupções dentro de um espaço já determinado, tendo o tempo como referência.

Assim, Fonseca (1995, p. 209) define que

Através da estruturação temporal a criança tem consciência da sua ação, o seu passado conhecido e atualizado, 0 presente experimentado e o futuro desconhecido é antecipado. Essa estrutura de organização é determinante para todos os processos de aprendizagem. A noção do tempo é uma noção de controle e de organização, quer ao nível da atividade, quer ao nível da cognitividade.

Podemos dizer que as estruturas de organização espacial e organização temporal são intimamente ligadas, pois: 


\begin{abstract}
A estruturação espaço-temporal emerge da motricidade, da relação com os objetos localizados no espaço, da posição relativa que ocupa o corpo, enfim das múltiplas relações integradas da tonicidade, da equilibração, da lateralização e da noção do corpo, confirmando o princípio da hierarquização dos sistemas funcionais e da sua organização vertical (FONSECA, 1995, p. 203).
\end{abstract}

g) A lateralidade é a capacidade de vivenciar os movimentos utilizandose, para isso, os dois lados do corpo; ora o direito, ora o esquerdo. Segundo Pacher (2006), a lateralidade pode ser definida como a presença da conscientização integrada e simbolicamente interiorizada dos dois lados do corpo (lado esquerdo e lado direito), o que pressupõe a noção da linha média do corpo.

Sendo assim, definimos a lateralidade como predomínio a um dos hemisférios durante a iniciativa da organização do ato motor. Isso acontece com as relações de orientação da face dos objetos, das imagens e dos símbolos, razão pela qual a lateralização vai interferir nas aprendizagens escolares de uma maneira decisiva.

Segundo Alves (2005), é somente a partir dos sete anos de idade que a criança será capaz de perceber que direita e esquerda funcionam complementando uma a outra, em uma relação de dependência também da posição das outras pessoas em relação a si e de sua posição de movimentação.

\title{
2.2 A psicomotricidade na Educação Infantil
}

O ser humano tem seu primeiro contato com o mundo através do movimento. Assim, toda a sua vida será influenciada pela percepção do seu corpo e suas peculiaridades de força e habilidades. Ou seja, o movimento é um dos principais fatores que proporciona ao homem o desenvolvimento físico que o acompanhará por toda a vida, desde sua infância até a fase adulta.

A Psicomotricidade, então, proporciona ao indivíduo um melhor domínio do seu corpo, sendo fator essencial e indispensável ao desenvolvimento global e uniforme da criança. Esse desenvolvimento das habilidades básicas de uma maneira mais sistemática é visto na pré-escola, e tem a função de fornecer à 
criança os pré-requisitos necessários para a aprendizagem da leitura e da escrita.

A educação psicomotora deve, portanto, ser considerada como a educação de base na Educação Infantil, pois ela condiciona todos os aprendizados nessa fase e leva a criança a tomar consciência de seu corpo, da lateralidade, a situar-se no espaço, a dominar seu tempo e a adquirir habilmente a coordenação de seus gestos e movimentos.

Nesse sentido, a psicomotricidade deve ser praticada durante toda a infância e ser conduzida com perseverança, permitindo, assim, prevenir inadaptações difíceis de corrigir quando já estruturadas (LE BOULCH, 1987, p.11).

Ela permite a compreensão de como a criança percebe e toma consciência do seu corpo e das possibilidades de se interagir e expressar por meio dele. Assim, para que ela seja bem trabalhada, necessita que sejam utilizadas as funções motoras, perceptivas, cognitivas, afetivas e sócio motoras, pois com isso a criança explora o ambiente, realiza experiências concretas e é capaz de tomar consciência de si mesma e do mundo que a cerca.

O conceito de corpo não pode ser ensinado. Assim, quando a criança consegue desenhar o seu próprio corpo é porque ela já o tem internalizado, já possui uma imagem mental dele, que é criada à medida que brinca com ele, explora-o e o usa.

Segundo Bueno (1998), a fase que se caracteriza como crucial para o desenvolvimento global do sujeito, tanto na parte motora quanto na intelectual e socioemocional, corresponde à faixa etária do nascimento até os 8 anos aproximadamente.

É nesse período que as principais dificuldades se instalam e, se as questões psicomotoras não forem bem trabalhadas, bem exploradas a tempo, certamente trarão prejuízos como dificuldades na escrita, na leitura, na fala, na sociabilização, entre outros. Assim, faz-se necessária a educação psicomotora tanto para a prevenção e tratamento das dificuldades quanto para a exploração do potencial ativo de cada indivíduo. 
Fonseca (1995a) coloca que a psicomotricidade pode possibilitar meios de prevenção e intervenção nas Dificuldades da Aprendizagem, além de poder ser um ótimo recurso para desenvolver potenciais de aprendizagens. Contudo, esses fatores somente poderão ser evidenciados se a prática psicomotora for bem elaborada e estruturada.

Segundo Negrine (1995, p. 25),

\begin{abstract}
Seja qual for à experiência proposta e o método adotado, o educador deverá levar em consideração as funções psicomotoras (esquema corporal, lateralidade, equilíbrio etc.) que pretende reforçar nas crianças com as quais está trabalhando. Mesmo levando em conta que, em qualquer exercício ou atividade proposta, uma função psicomotora sempre se encontra associada a outras, o professor deverá estar consciente do que exatamente está almejando e onde pretende chegar.
\end{abstract}

Assim sendo, observa-se a importância em se desenvolver atividades psicomotoras que objetivem atender todas as necessidades das crianças, pois estas dependem de bons mediadores para que o processo de aprendizagem ocorra com êxito.

O trabalho psicomotor auxilia de modo significativo o processo de aprendizagem na primeira infância uma vez que, com o exercício de tais atividades, o professor terá a possibilidade de interagir com a criança, de manter um contato direto com ela.

Bueno (1998, p. 58) afirma que, "a criança se sentirá bem na medida em que seu corpo Ihe obedece, em que o conhece bem, em que pode utilizá-lo não somente para movimentar-se, mas também para agir". Por isso, o trabalho com o movimento na infância torna-se imprescindível.

Assim, segundo o Ministério da Educação (BRASIL, 1998, p. 29),

Os conteúdos deverão priorizar o desenvolvimento das capacidades expressivas e instrumentais do movimento, possibilitando a apropriação corporal pelas crianças de forma que possam agir com cada vez mais intencionalidade. Devem ser organizados num processo contínuo e integrado que envolve múltiplas experiências corporais, possíveis de serem realizadas pela criança sozinha ou em situações de interação. Os diferentes espaços e materiais, os diversos repertórios de cultura corporal expressos em brincadeiras, jogos, 
danças, atividades esportivas e outras práticas sociais são algumas das condições necessárias para que esse processo ocorra.

Diante desse cenário, é importante a reflexão sobre as práticas da Educação ainda vigentes no nosso país. A compreensão dos benefícios da Psicomotricidade para o processo de ensino-aprendizagem infantil é importante para que possamos repensar e recriar as metodologias de ensino, possibilitando às crianças uma educação mais adequada à sua realidade por meio de um aprender cercado de motivações e movimentos.

Como afirma Fonseca (2008 apud GONÇALVES, 1983, p.27),

\begin{abstract}
É por meio da atividade motora que a criança vai construindo um mundo mental cada vez mais complexo, não apenas em conteúdo, mas também em estrutura. O mundo mental da criança, devido às ações e interações com o mundo natural e social, acaba por apresentar essas realidades por meio de sensações e imagens dentro de seu corpo e do seu cérebro. Primeiro pela intervenção de outras pessoas, que atuam como mediadoras entre a criança e o mundo; depois pelos sucessos e insucessos da sua ação, ela vai adquirindo experiências que virão a ser determinantes no seu desenvolvimento psicológico futuro.
\end{abstract}

É determinante o reconhecimento da importância da psicomotricidade na Educação Infantil para que, assim, a criança possa se desenvolver de forma global. Como afirma Sánchez (2003), é na prática da psicomotricidade que a criança desenvolve a plenitude motora, estando assim a aprendizagem da criança ligada diretamente ao desenvolvimento psicomotor.

$\mathrm{O}$ trabalho psicomotor bem direcionado reflete uma prática pedagógica preocupada com o desenvolvimento total da criança.

Sendo assim, não podemos, de maneira nenhuma, menosprezar a importância do trabalho de base com a psicomotricidade. Esse trabalho se torna expressivo e deve nortear o processo de ensino-aprendizagem em toda a Educação Infantil, favorecendo o desenvolvimento completo e rico de significado. 


\section{CONCLUSÃO}

Percebemos com esse estudo que a Educação Psicomotora é um instrumento educativo riquíssimo e que perpassa por todo o processo educativo. É, portanto, indispensável nas atividades escolares, no desenvolvimento infantil e no processo de ensino-aprendizagem. Essa importância do trabalho motor na educação se torna perceptível por sua contribuição para o desenvolvimento global das crianças.

No decorrer da pesquisa, pudemos observar que o bom direcionamento motor contribui significativamente para o desenvolvimento físico, cognitivo e afetivo da criança. Ou seja, a escola deve proporcionar às crianças diversas experiências, estimulando o desenvolvimento das habilidades psicomotoras necessárias para o aprendizado completo.

A Psicomotricidade deve ser trabalhada, portanto, em toda a educação infantil, respeitando a faixa etária e nível de cada aluno e levando em consideração as necessidades, potencialidades e as características individuais de cada criança e o seu grau de maturidade. Para isso, é preciso adotar sempre diferentes estratégias de implementação e trabalho da psicomotricidade, como atividades lúdicas em que o desenvolvimento motor, o cognitivo, o social e o afetivo são favorecidos pelo ato de brincar.

Assim, observamos, neste estudo, que a estimulação psicomotora correta contribui para uma aprendizagem completa e significativa e é de extrema importância na Educação Infantil, uma vez que desempenha um papel fundamental para as aprendizagens.

Ressaltamos ainda que a psicomotricidade é apenas um meio de auxiliar a criança a superar suas dificuldades de aprendizagem e a prevenir possíveis inadaptações, auxiliando na alfabetização. É válido salientar que não pretendemos aqui considerá-la como uma forma de resolver todos os problemas encontrados em sala de aula, mas uma ferramenta importante para a eficácia do processo.

Sendo assim, confirmamos então a importância da psicomotricidade para a Educação Infantil, pois, com o desenvolvimento das habilidades psicomotoras bem direcionadas e estruturadas, é possível um grau de aprendizagem 
satisfatório que gere um processo de ensino-aprendizagem favorável ao desenvolvimento afetivo, cognitivo e intelectual do aluno e ao encaminhamento de uma evolução integral das crianças.

\section{REFERÊNCIAS}

ALVES, Fátima. Psicomotricidade: Corpo, Ação e Emoção. Rio de Janeiro. Wak, 2005.

ASSUNÇÃO, E. e COELHO, José Maia Tereza. Problemas de Aprendizagem. São Paulo: Ática, 1997.

BRASIL. Ministério da Educação. Secretaria de Educação Fundamental. Referencial curricular nacional para a educação infantil. Brasília, DF: MEC/SEF, 1998.

BUENO, Jocian Machado. Psicomotricidade: teoria e prática. São Paulo: Lovise, 1998.

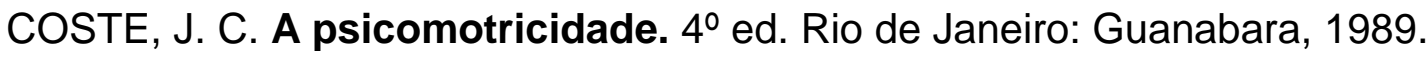

A psicomotricidade. Álvaro Cabral (trad.). Rio de Janeiro: Editora Guanabara, 1992.

FONSECA, V. da. Psicomotricidade: perspectivas multidisciplinares. Porto Alegre: Artmed, 2004.

Artes Médicas, 1995a.

da. Introdução às dificuldades de aprendizagem. Porto Alegre:

GALLAHUE, David L. Compreendendo o desenvolvimento motor: bebês, crianças, adolescentes e adultos. São Paulo: Phorte Editora, 2003.

GONÇALVES, Fátima. Do andar ao escrever: um caminho psicomotor. São Paulo, 2008.

Do andar ao escrever: um caminho psicomotor. São Paulo: Cultural RBL LTDA, 1983. 
LAPIERRE, André; AUCOUTOURIER, Bemard. Fantasmas Corporais e Prática Psicomotora. São Paulo: Ed. Manole, 1984.

LE BOULCH, Jean. A educação pelo movimento: a psicocinética na idade escolar. Porto Alegre: Artes Médicas, 1984.

O desenvolvimento psicomotor: Do nascimento aos 6 anos. Porto Alegre: Artes Médicas, 1986.

. Educação psicomotora: psicocinética na idade escolar. trad. Jeni Wolff. Porto Alegre: Artes Médicas, 1987.

. O desenvolvimento psicomotor: Do nascimento aos 6 anos. $7^{\mathrm{a}} \mathrm{Ed}$, Porto Alegre: Artes Médicas, 2001.

NETO, P. Brincando com as Frações: Sistema de Jogos Educativos. Canoas: ULBRA, 2001.

OLIVEIRA, G. C. Psicomotricidade: Educação e reeducação num enfoque psicopedagógico. 12. ed. Petrópolis: Vozes, 2007.

Psicomotricidade: Educação e Reeducação num enfoque Psicopedagógico. 5aㅡ edição. Petrópolis: Editora Vozes, 2001.

ROSA NETO, F. Manual da Avaliação Motora. Porto Alegre: Artemed, 2002.

SÁNCHEZ, P. A.; MARTÍNEZ, M. R.; PEÑALVER, I. V. A psicomotricidade na educação infantil: uma prática preventiva e educativa. Tradução Inajara Haubert Rodrigues. Porto Alegre: Artmed, 2003.

SBP. SOCIEDADE BRASILEIRA DE PSICOMOTRICIDADE. Disponível em: www.psicomotricidade.com.br.

VAYER, P. O equilíbrio corporal - uma abordagem dinâmica dos problemas da atitude e do comportamento. Trad. Maria Aparecida pasbt. Porto Alegre: Artes médicas, 1984.

WALLON, H. A Evolução Psicológica da Criança. São Paulo: Edições 70, 1968.

Do ato ao pensamento: ensaio de psicologia comparada. Trad. J. Seabra Dinis. Lisboa: Moraes, 1979. 
Psicologia e educação da infância. Lisboa: Estampa, 1981. 